\title{
Remote Real -Time Process and Production Monitoring Mechanism of Lighting Parts FOR OUTDOOR RECREATION
}

\author{
Cheng-I Hou ${ }^{1}$, Han-Chen Huang ${ }^{2 *}$, Tian-Syung Lan ${ }^{1}$, Wei-Min Teng ${ }^{1}$ \\ ${ }^{1} \mathrm{Yu}$ Da University of Science and Technology, Taiwan \\ ${ }_{2 *}$ Corresponding Ahthor Chung Hua University, Taiwan
}

\begin{abstract}
This study collected and analyzed Light-Emitting Diode (LED) parameters (forward conduction voltage VF, reversed breakdown voltage, and reversed linkage current) and output information in testing LED back-end process and packaging. Moreover, it developed a remote control operation platform using LabVIEW of national instruments (NI), and provided an interface for user operation, data storage analysis, and specification evaluation. Accordingly, a remote real-time process monitoring and automatic production specification checking mechanism can be developed to replace traditional manual quality control operation, which directly deliver light-emitting diodes, while reducing high labor and production costs. Through evaluation of the proposed real-time process capability, the collected light-emitting diode parameters are automatically adjusted to the production specifications, which meet the process capability and are returned to the testing instrument in real time. The products can thus meet the process capability of the batch, the rework rate can be effectively reduced, and the passing rate of delivery quality control can be improved. The proposed remote real-time process monitoring and automatic production specification checking mechanism can analyze and evaluate production specification data, and monitor and store historical data for the long term in conjunction with the database system. Moreover, the light-emitting diode can be automatically checked by the evaluation process capability in order to improve production technology and process parameters. Thus, a solution for the optimization of light-emitting diode parameter specifications can be established to promote effective management of production equipment, improve production efficiency, and integrate production flow.
\end{abstract}

\section{KEYWORDS}

Remote Monitoring, Real-Time Evaluation, Process Capability, Man-Machine Interface.

\section{Research Background and Motives}

Light-Emitting Diode (LED) is an electronic component capable of emitting light. In its early days, the electronic component only emitted a red light of low luminous intensity, and then developed other monochromatic lights. To date, LED can emit visible light, infrared rays, and ultraviolet lights with high luminous intensity. As the white light-emitting diode emerges, LED has been widely applied to lighting. LED features high efficiency, long service life, quick response, and high reliability, and is not easily damaged, thus, it is very suitable for lighting outdoor recreation areas. The luminous efficiency of the white light-emitting diode has made progress in recent years, and the cost for every kilolumen has been greatly reduced due to the inflow of a large amount of investment. However, even though LED costs remain higher than other traditional lighting, LED has been increasingly applied to lighting.

In recent years, many factories have relocated to Mainland China, and Taiwanese manufacturers have proposed relevant manufacturing strategies in response to this trend. The industry automation and integrated manufacturing of computers are two approaches to break through the status quo. 
During production, testing is an indispensable operation to improve product quality, as production specification appropriateness determines product quality and production costs, which may affect corporate market competitiveness; the real time evaluation of production specifications and optimal production control mechanism is required to maximize profits and increase competitiveness.

Normally, the product specifications in an automatic testing system are derived from customer specifications, meaning production specifications derived from customer specifications cannot fully meet the process level of the batch. In this case, products may be rejected during delivery quality control if in-house testing does not evaluate and control production specifications. Such product batches must be reworked in the production system, resulting in unnecessary losses.

In order to ensure production quality, effectively use finite testing resources, and improve performance of production system, one set of real-time production specification evaluation and control mechanism is required to automatically check production specifications, which is an effective approach to improve product quality and reduce production costs.

The current research is limited to real-time monitoring of process equipment information and remote control of process equipment, and while the relevant quality process capability can be effectively recorded, it can reflected by the tested specifications of the testing instruments. Thus, this study is aimed to establish a mechanism that can calculate and send testing data to the testing instruments in order to reflect the process capability of this batch; the approach to reflect the specifications of the process capability in advance can effectively improve the OQC pass index of finished products.

In testing of the LED back end process and packaging, this study used the open Microsoft Windows work platform, which provides a database function to collect the results of LED testing instruments. The collected data are provided for remote and near-end users, who use designed analysis programs to learn real-time production system status and historical data via the Internet; the proposed real-time process capability evaluation method can be used to automatically adjust production specifications to meet process capability by calculating the LED parameters collected from the packing machine, which are returned to the testing instrument. Thus, products produced according to this solution shall meet process capability, effectively reduce the rework rate, improve the OQC Pass Index, and reduce unnecessary costs and time resulted from reworking.

\section{LITERATURE REVIEW}

\section{(1) LED characteristics and parameters}

Light-Emitting Diode (LED) is a double terminal device. The electronic symbol is as shown in Figure 1.

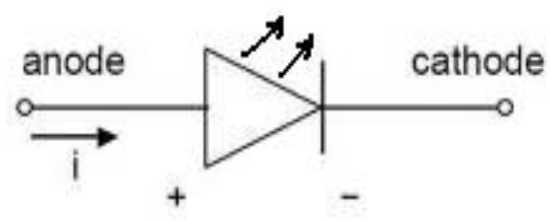

Figure 1. LED electronic symbol

LED is a p-n junction consisting of $\mathrm{p}$ type semiconductor and $\mathrm{n}$ type semiconductor. The space charge layer is formed on the both sides of the connection, and an electronic field is established. LED is one of the important semiconductors devices, and has been widely applied [1]. 
In the case of reversed voltage bias, external electronic and built-in fields shall be further reinforced to form a reverse saturation current within a reversed voltage range not related to the reversed bias voltage. When the external reversed voltage reaches a certain degree, the electronic field intensity in the p-n junction space charge layer reaches a critical value and produces carrier multiplication and many electron hole pairs, thus, too large reversed breakdown current occurs, called LED diode through [2]. An important feature of LED is its one-way conductivity circuit, where current flows into the LED anode and flows out the cathode (Figure 2).

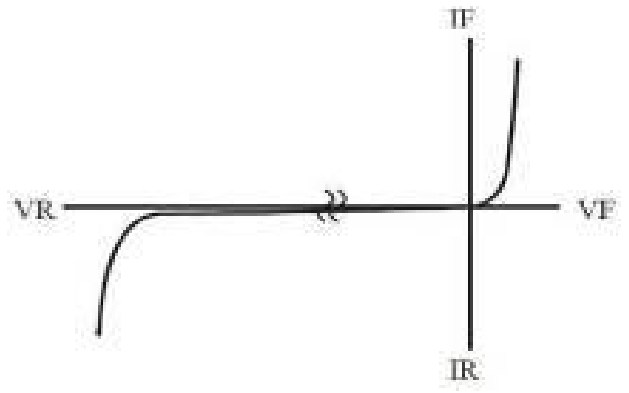

Figure 2. LED performance curve

In an electronic circuit, the LED anode is connected to the high potential end, and cathode is connected to the low potential end, and LED can be connected. This connection is called the forward bias. After connection, the voltages on the two ends of the LED remain unchanged, called LED forward voltage [3].

In electronic circuits, the LED anode is connected to the low potential end, and the cathode is connected to high potential end. At this time, no current flows through LED, which is in the cut-off state. This connection is called reversed bias [4]. If LED has a reversed bias, weak reserved current may flow through the LED, called linkage current. When the LED reversed voltage is increased to a certain value, the reversed current can be sharply increased, and LED may loss one-way conductivity, which state is called LED through.

\section{(2) Monitoring system}

Generally, the signal transmission of the automatic factory monitoring system (Figure 3) uses serial communications RS-232, RS-422, and RS-485; currently, few process companies have a remote monitoring system, and software companies specialized in research and development for relevant equipment products. Remote network monitoring technology is mature and widely used in foreign countries; and while domestic technologies have been increasingly improved, its application is not popular and technologies seldom play a role [5]. If the relevant domestic technologies can be fully applied to the industry, they can play an important part in networks and monitoring.

\section{(3) Process capability}

Simply put, the SPC (Statistical Process Control) is a method that uses a series of statistical methods and processes for monitoring and improvement of quality control by targeting key processes $[6,7]$. If a process has deviation, it can be observed and corrected through quality control tools. SPC can make products meet specification needs, and continuously eliminate process variability to improve quality. 


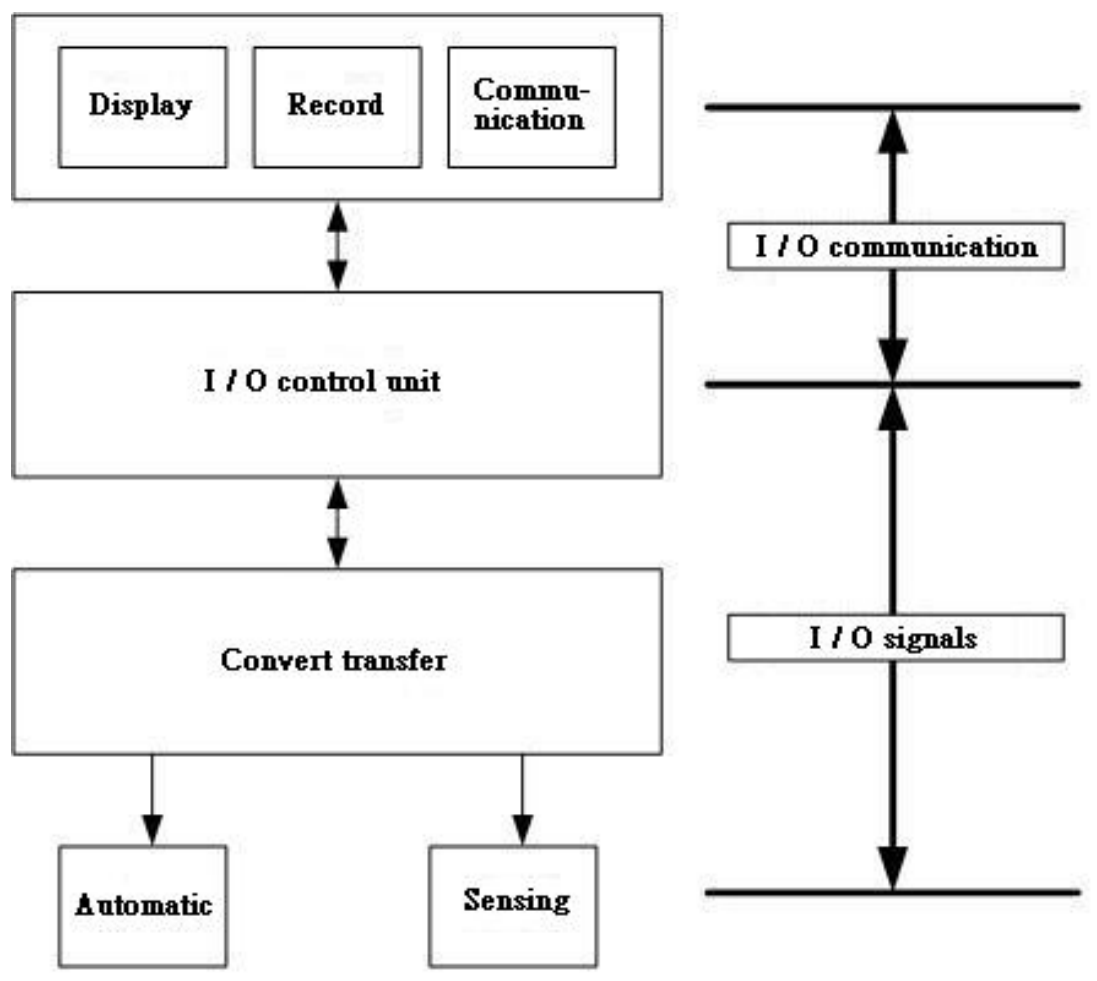

Figure 3.General monitoring system

Process capability indices are effective tools to measure process capability and performance. In manufacturing, process capability indices are used to evaluate whether manufactured products meet specifications required by customers. The two process indices $\mathrm{Cp}$ and $\mathrm{Cpk}$ are often used in industry, and are defined according to process yield, thus, they can reflect the process reject ratio [8-10].

\section{RESEARCH METHOD AND BASIC STEPS}

In combination with LabVIEW program software, Light-Emitting Diode (LED) sorting machines use the RS-232 communication interface to send LED parameters forward voltage VF, reversed breakdown VR, and reversed leakage current IR, to the main computer in order to achieve real-time monitoring of packing machines and production specifications. The data returned to the tables is converted and stored in the database to save finite hard disk space. Meanwhile, management can inquire the relevant production conditions and historical data through Ethernet, which are sent for remote diagram supervision and automatic measurement. The evaluation parameters obtained from process capability analysis are used as upper and lower limits for new tested specifications, where production specifications are repeatedly checked according to the set time (VF, VR, and IR). Thus, a "remote real-time monitoring and production specification automatic checking mechanism," with a friendly human-machine interface, is developed.

In this study, the system development life-cycle method is used as the research core. After system analysis, the application process flow is as follows:

When users want to produce a specific batch, an RFID READER can be used for read-in; when the human-machine graphic interface receives the production batch data, the internal specification 
data system can automatically send the internal specification database to the LED testing instrument via serial port. After production, the LED testing instruments send the test results to the results data system, which adds the tested result and time sequence codes, and sends them to the testing result database. When the human-machine graphic interface receives 1000 testing data, the proposed production specification evaluation and control mechanism is used to calculate and send the tested specifications to the LED instrument. Finally, the testing data and unit output of the production process can be displayed on the network through the human-machine graphic interface.

In this research, the system can be divided into a hardware system (Figure 4) and a software system (Figure 5). The hardware system is responsible for data collection and transmission; the software system is responsible for data processing, operation, and induction.

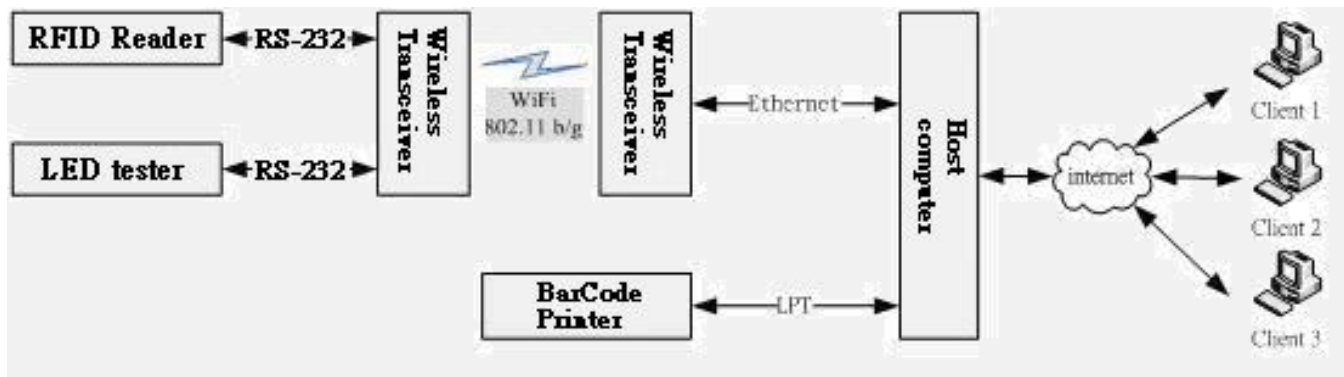

Figure 4. Hardware system architecture

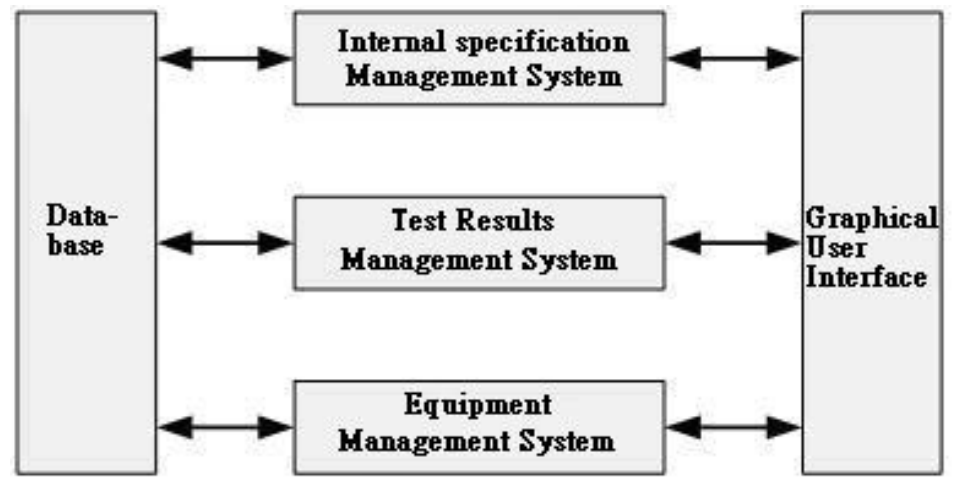

Figure 5. Software system architecture

This system graph monitoring program is designed and developed through National Instruments LabVIEW 8.2. The human-machine interface would receive the first 1000 testing data, and the production specification evaluation and control mechanism (Figure 6) is used to calculate testing specifications, and the testing specifications are sent back to the LED instruments. After completion of the batch production, the user may notify the software through the human-machine interface. The testing result system converts the collected testing results into frequency tables for recording. In terms of time sequence codes, the unit output per unit time can be used as records. The testing results and unit output in the production process can be graphically displayed. 
International Journal of Computer Science \& Information Technology (IJCSIT) Vol 6, No 4, August 2014
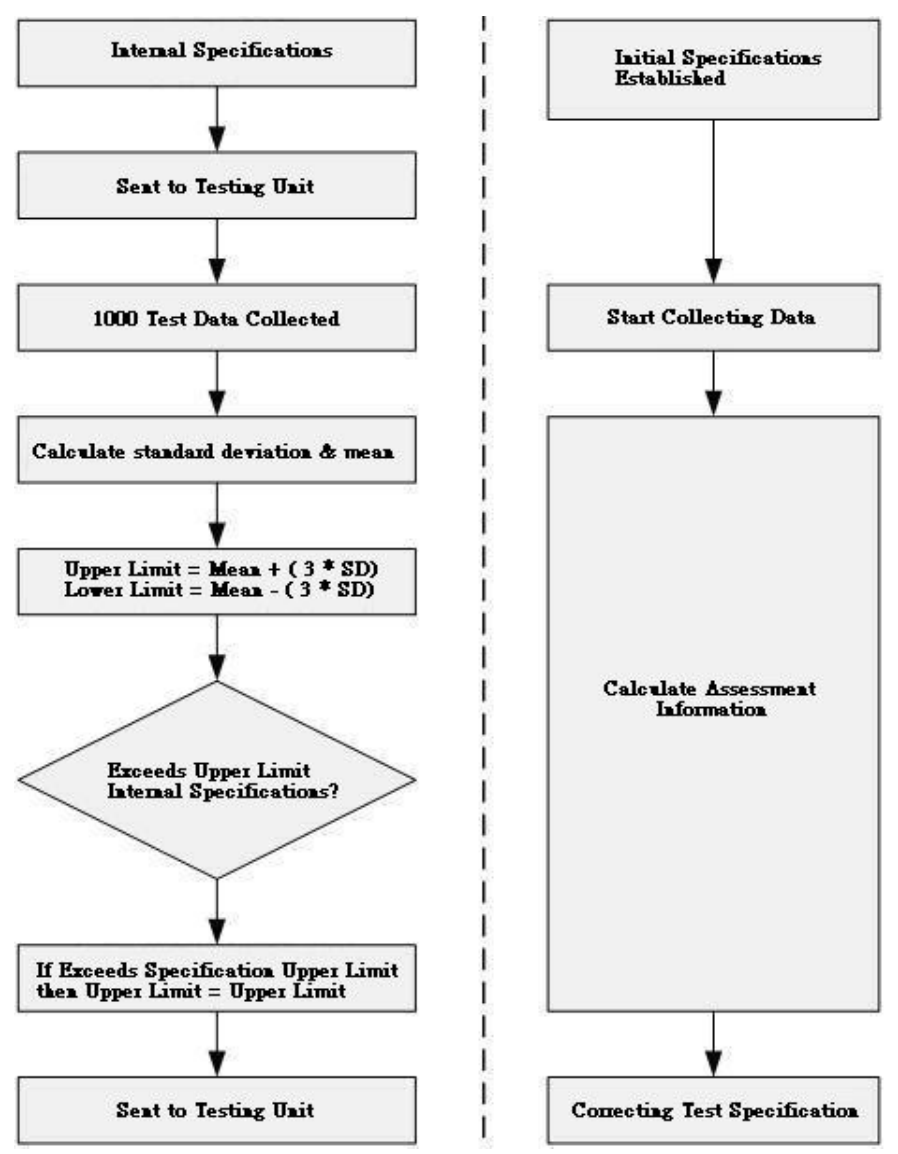

Figure 6. Production specification evaluation and control mechanism

The LabVIEW application program is compiled through front panel and program block diagrams. The main function of the front panel is the human-machine interface, while the main functions of the program block flow diagram include program logic and operation, which are described, as follows:

The front panel is the graphic user interface, namely, the VI virtual instrument panel. The interface consists of two modules: user input and display output, and has switches, knobs, and other controls and indicators. Thus, the front panel is combined with input controls and indicators, and functions the same as an actual instrument control panel, can be designed (Figure 7). 
International Journal of Computer Science \& Information Technology (IJCSIT) Vol 6, No 4, August 2014

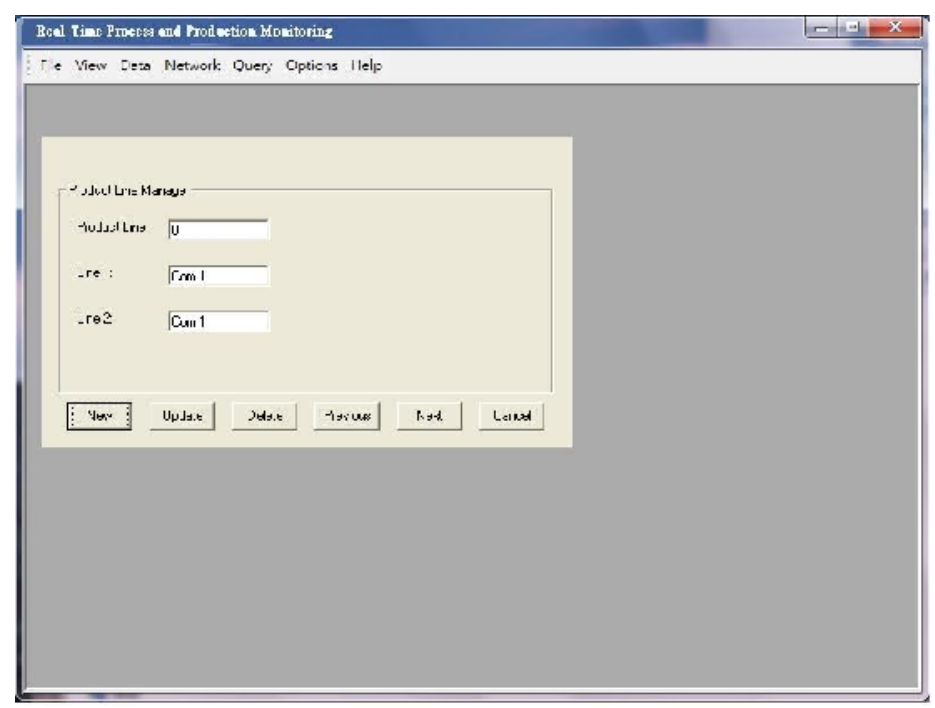

Figure 7. LabVIEW front panel

\section{RESUlts ANALYSIS}

This system operation interface can be displayed on Internet Explorer, and the equipment data system management interface (Figure 8) is responsible for setting the LED instrument serial port number of the tested packing machine to the equipment database. Each production line is equipped with two LED instruments, thus, there are two RS-232 ports.

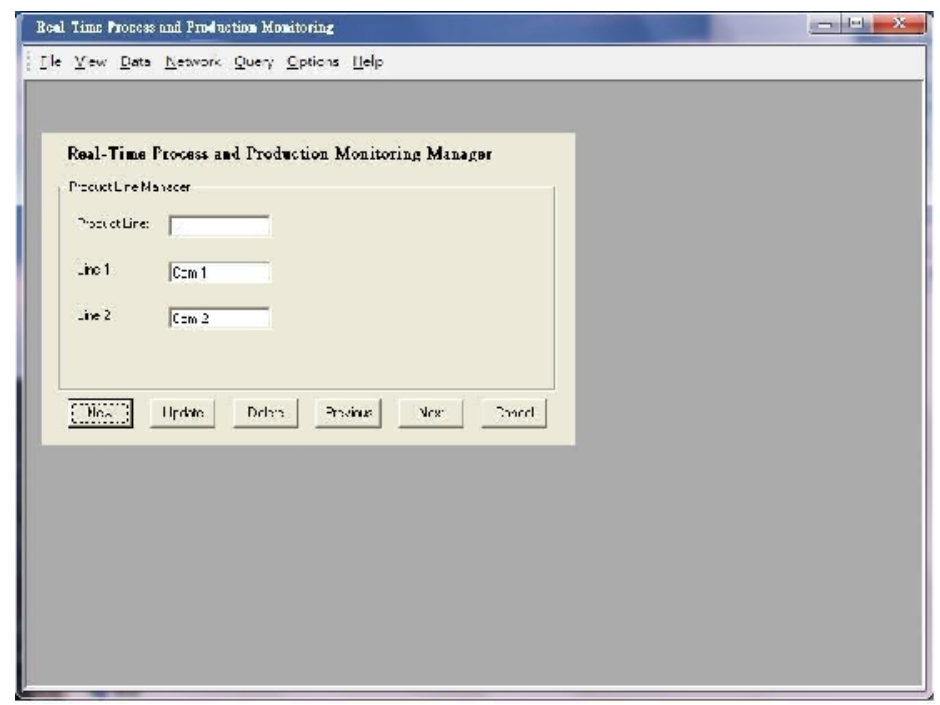

Figure 8. Management interface of equipment data system

The testing result data system management interface is as shown in Figure 9. The production batch number, LED P/N, and number of used production lines, are set in the testing result database. 


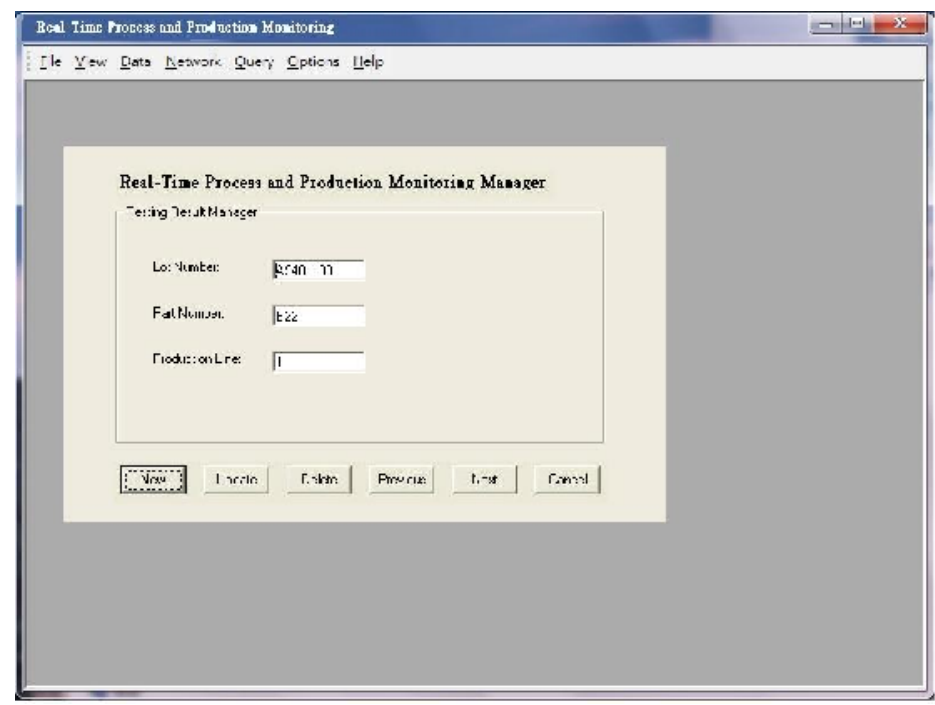

Figure 9.Interface of testing result data management system

In this study, the use of a serial device to connect Ethernet enables users to set remote devices and equipment through network access and management in any place; which is different from the concept of each serial port device requiring one computer, and serial servers can reduce computer costs for enterprises. Through LabVIEW, complicated and outsourced programs, originally compiled by professionals, can be easily and rapidly complied by engineering staff, enabling better alignment with goals.

\section{CONCLUSION}

The internal specification data system management interface (Figure 10) is responsible for establishing the testing conditions for LED instruments with different $\mathrm{P} / \mathrm{N}$ and specification parameters in the internal specification database.

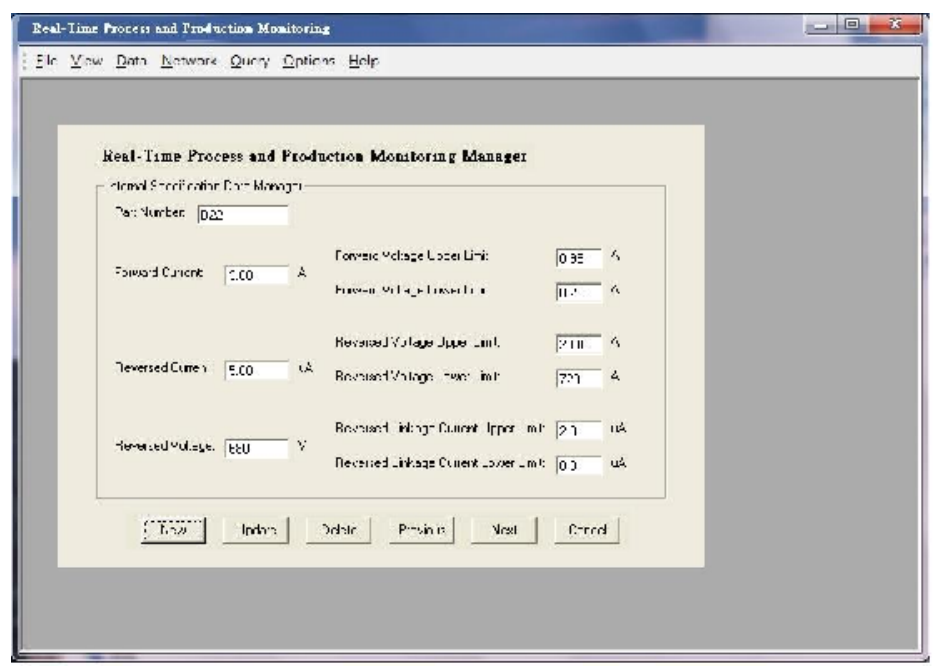

Figure 10. Internal specification data system management interface

In addition to the descriptions of software and hardware plans for a real-time monitoring and adjustment system, this study completed system testing in order to verify system stability. By 
real-time process capability evaluation, the collected LED parameters are adjusted to meet process capabilities after SPC, which are returned to the testing instrument in real time, thus, products can meet process capability.

By using the LabView Internet Toolkit, the compiled programs can be directly displayed on the Internet via the web, while general webpage programs cannot be recompiled using webpage programs, and recompilation may waste labor and time. After verification, the system data analysis function can be introduced to human-machine operation interface system to achieve real-time analysis; through long term data collection, the optimal process parameters are analyzed through different processes to improve overall production efficiency.

This study uses a Microsoft Windows work platform and provides a database function through which the testing results of the LED instruments are collected. The collected data can be provided for remote and near-end process staff and users, who can know real-time system status and historical data through the designed analysis method. If instruments applicable to technologies can have more types, the overall production management system performance will be greatly improved.

\section{REFERENCES}

[1] R. Boyer, (2000)"Is a Finance-led growth regime a viable alternative to Fordism? A preliminary analysis", Economy and Society, Vol. 29, No. 1, pp. 111-145.

[2] T. Komine, M. Nakagawa, (2004)"Fundamental analysis for visible-light communication system using LED lights", IEEE Transactions on Consumer Electronics, Vol. 50, No. 1, pp. 100-107.

[3] J. Xu, M.F. Schubert, A.N. Noemaun, D. Zhu, J.K.Kim, F. Schubert, M.H. Kim, H.J. Chung, S.Yoon, C. Sone, Y.J. Park, (2009)"Reduction in efficiency droop, forward voltage, ideality factor, and wavelength shift in polarization-matched GaInN/GaInN multi-quantum-well light-emitting diodes", Applied Physics Letters, Vol. 94, No. 1, pp. 011113 - 011113-3.

[4] D. Zou, M. Yahiro, T. Tsutsui, (1998)“'Improvement of current-voltage characteristics in organic light emitting diodes by application of reversed-bias voltage”, Japanese Journal of Applied Physics, Vol. 37 , No. 11B, pp. L1406-L1408.

[5] S. Zhou, W. Ling, Z. Peng, (2007)“'An RFID-based remote monitoring system for enterprise internal production management”, The International Journal of Advanced Manufacturing Technology, Vol. 33, No. 7, pp. 837-844.

[6] W.H. Woodall, (2000)“Controversies and contradictions in statistical process control”, Journal of Quality Technology, Vol. 32, No. 4, pp. 341-350.

[7] M. Kano, S. Hasebe, I. Hashimoto, H. Ohno, (2004)“Evolution of multivariate statistical process control: application of independent component analysis and external analysis", Computers \& Chemical Engineering, Vol. 28, No. 6, pp. 1157-1166.

[8] P.H. Liu, F.L. Chen, (2006)"Process capability analysis of non-normal process data using the Burr XII distribution", The International Journal of Advanced Manufacturing Technology, Vol. 27, No. 9, pp. 975-984.

[9] K.L. Hsieh, (2006)“The study of cost-tolerance model by incorporating process capability index into product lifecycle cost”, The International Journal of Advanced Manufacturing Technology, Vol. 28, No. 5, pp. 638-642.

[10] C.H. Wang, (2005)“Constructing multivariate process capability indices for short-run production”, The International Journal of Advanced Manufacturing, Vol. 26, No. 11, pp. 1306-1311. 